\title{
Effect of Deposition Pressure on the Microstructure and Corrosion Resistance of Diamond-Like Carbon Films Prepared by Plasma Enhanced Chemical Vapor Deposition
}

\author{
Shanshan $W^{1,2}$, Yiwen Zhang ${ }^{1,2, *}$, Zhong $W^{2, *}$, Zhenbo Qin ${ }^{2}$, Haoyu Chen ${ }^{1,2}$, and Wenbin Hu ${ }^{1,2}$ \\ ${ }^{1}$ Key Laboratory for Advanced Ceramics and Machining Technology of Ministry of Education, \\ Tianjin University, Tianjin 300072, People's Republic of China \\ ${ }^{2}$ School of materials science and engineering, Tianjin University, 300072, People's Republic of China \\ *E-mail: ywzsci@tju.edu.cn, wuzhong2319@163.com
}

doi: $10.20964 / 2010.01 .50$

Received: 3 SEptember 2019 / Accepted: 28 October 2019 / Published: 30 November 2019

To improve the corrosion resistance of biomedical stainless steel in bodily fluids, a diamond-like carbon (DLC) film deposited on steel has been developed by plasma enhanced chemical vapor deposition (PECVD) technology using methane and argon as gas sources. Through adjusting the deposition pressure, DLC films with different microstructure can be obtained. Upon an increase in pressure from 0.6 to $3 \mathrm{~Pa}$, the degree of graphitization of the DLC film first increases and then decreases. The formation of small graphite clusters releases internal stress in the material and increases the density of the DLC film. Meanwhile, the increase in density prevents electrolyte diffusion to the substrate surface, which increases corrosion resistance. At a pressure of $1 \mathrm{~Pa}$, the degree of graphitization is relatively high with an ID/IG value of 0.6, and a more dense DLC film is obtained. From the electrochemical impedance spectroscopic (EIS) fitting results, the charge transfer resistance in $0.9 \mathrm{wt} . \% \mathrm{NaCl}$ solution is higher than $6 \times 10^{8} \Omega \cdot \mathrm{cm}^{2}$, i.e. the corrosion of the substrate is very slow. At a deposition pressure of around $1 \mathrm{~Pa}$, the DLC film shows obvious protection of the stainless steel substrate.

Keywords: PECVD, DLC film, deposition pressure, microstructure, graphitization degree, corrosion resistance

\section{FULL TEXT}

(C) 2020 The Authors. Published by ESG (www.electrochemsci.org). This article is an open access article distributed under the terms and conditions of the Creative Commons Attribution license (http://creativecommons.org/licenses/by/4.0/). 